Artigo recebido em

22/01/2014

Aprovado em

$14 / 02 / 2014$

MARTA REGINA

MAIA

Universidade Federal de

Ouro Preto -

marta@martamaia.pro.br

Professora Adjunta III

do curso de Jornalismo

da UFOP. Doutora em

Ciências da

Comunicação pela USP.

Líder do Grupo de

Pesquisa "Jornalismo,

Narrativas e

Práticas Comunicacionais"

THALES VILELA

LELO

Universidade Federal de Minas Gerais -

thales.lelo@gmail.com

Mestrando em

Comunicação Social pela

UFMG. Membro do Grupo

de Pesquisa "Jornalismo,

Narrativas e Práticas

Comunicacionais"
Estudos em Jornalismo e Mídia

Vol. 11 No 1

Janeiro a Junho de 2014

ISSNe 1984-6924

\section{A morte de Vladimir Herzog: narrativas do trauma na memória coletiva}

Marta Regina Maia e Thales Vilela Lelo

\section{Resumo}

Este trabalho faz uma discussão sobre a morte do jornalista Vladimir Herzog a partir daqueles que sofreram torturas no regime militar. O principal objeto de análise será o documentário "Vlado: 30 anos depois", produzido pela TV Cultura e dirigido por João Batista de Andrade. A proposta metodológica se baseia em uma análise de conteúdo ancorada no paradigma indiciário, tomando o filme como um indicador da vida social (em diálogo com o contexto histórico no qual está inserido). As averiguações empreendidas indicam que as vítimas da ditadura narram suas histórias não por um desejo singular, mas por preocupação para com uma história que poderia ser esquecida em razão da ausência de imagens que pudessem expressar suas dores, o que, entretanto, não impede a sua lembrança pelos meios de comunicação e pelo jornalismo em especial.

Palavras-chave

Ditadura, memória, experiência.

\section{Abstract}

This paper performs a discussion about the death of journalist Vladimir Herzog starting from whose who have suffered tortures in the military regime. The main object of analysis is the documentary "Vlado: 30 anos depois", produced by TV Cultura and directed by João Batista de Andrade. The methodology is based on a content analysis grounded in evidentiary paradigm, taking the film as an indicator of social life (in dialogue with the historical context in which it is inserted). The investigations undertaken indicate that the dictatorship's victims narrate their stories not by a singular desire, but by concern for a story that could be overlooked because of the absence of images that could express their pain, which, however, does not preclude its remembrance by the media and journalism in particular.

Keywords

Dictatorship, memory, experience. 
1- Uma das evidências de que esta notícia ainda não foi devidamente "dada" é a reportagem feita pelo jornalista Lucas Ferraz, na Folha de S. Paulo, em 05/02/2012. Nesta matéria, o jornalista localiza, nos Estados Unidos, o fotógrafo que tirou as fotos de Herzog na época. $O$ fotógrafo Silvaldo Leung Vieira - que pela primeira vez fala à imprensa -, assume, nesta reportagem, que houve manipulação e que isso o teria levado a abandonar seu emprego público em 1979, quando fo $i$ para uma viagem de férias nos EUA.

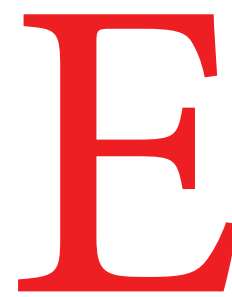

ste ano, se estivesse vivo, Vladimir Herzog faria 77 anos. Qual o poder desta lembrança para a história recente do Brasil? É que o assassinato deste jornalista simboliza a iniquidade de um período histórico que ainda guarda lacunas e traumas em processamento. A reverberação deste acontecimento atinge o século XXI porque seus familiares, e a sociedade de modo geral, ainda não conhecem os meandros deste e de muitos outros fatos que marcaram a ditadura militar no Brasil.

O ano é 1975, o lugar é São Paulo. Paulo Egydio Martins era o governador e Ernesto Geisel o presidente, após sucessivos militares na presidência desde o dia 31 de março de 1964, em que as Forças Armadas - com o argumento de que o país estava para se tornar uma ditadura sindicalista ou comunista - resolveram tomar o poder. A partir de então o país viveu sob a égide de atos institucionais que implantaram mecanismos de cerceamento da liberdade e dos direitos constitucionais.

Os meios de comunicação sofrem, nestas décadas, as consequências da repressão generalizada que o país atravessa. A história de Vladimir Herzog, entretanto, foi diferente de outras histórias do período, em que pessoas eram tiradas de suas casas sem qualquer tipo de presença legal. Ele, que também teve seu domicílio e trabalho invadidos por policiais, conseguiu adiar por um dia a sua ida para "prestar depoimento" na sede do DOI-CODI, com pleno conhecimento dos familiares e colegas de trabalho. Mal sabia que entraria naquele lugar para nunca mais sair.
Ao menos dois elementos contribuíram para a enorme repercussão do caso. $\mathrm{O}$ primeiro é que Vlado nunca havia tido posições radicais, o que teria gerado uma estranheza generalizada sobre sua detenção, e ainda, o segundo, é que era um jornalista, pessoa de visibilidade pública. Tendo assumido a direção de jornalismo da TV Cultura de São Paulo no dia 3 de setembro de 1975, havia apresentado à direção da emissora um documento intitulado "Considerações gerais sobre a TV Cultura", em que expunha sua preocupação com um telejornal que estimulasse a reflexão e que espelhasse os problemas, as esperanças e as angústias das pessoas (CULTURA RETRÔ, 2011). Acabou por sofrer uma espécie de campanha por alguns setores da imprensa, que indicavam o domínio "da esquerda na emissora do governo" (DANTAS, 2012, p. 154). Conseguiu assim atrair a atenção de certos dirigentes que não aceitavam ninguém que não seguisse estritamente as regras do jogo.

A divulgação de sua foto, emblemática do período ditatorial, em que aparece enforcado pelo cinto de seu macacão, com as pernas dobradas, contribuiu para acirrar os ânimos no interior da sociedade ${ }^{1}$. Este acontecimento também mostrou as tensões entre diferentes forças que estavam no poder. Como mostra Elio Gaspari(2004), amparado em documentos da época, o presidente Geisel questionava a falibilidade dos métodos utilizados pelas forças de repressão, com especial preocupação pela insubordinação militar (dado que em São Paulo ela aparecia de maneira mais evidente). Uma das provas dessa indisciplina foi a demissão, pelo presidente, do Comandante do II Exército, general Ednardo D’Avila Mello, 
logo após a morte do operário Manoel Fiel Filho, ocorrida 84 dias após a morte de Herzog ${ }^{2}$.

"Mataram o Vlado!", frase dita por Clarice Herzog, sua esposa, logo que uma comitiva da TV Cultura chegou em sua casa para justamente informar-lhe que a situação do jornalista teria se agravado, foi sendo replicado em quase todos os lugares, evidenciando a necessidade de se marcar este fato de maneira coletiva. Uma proposta de D. Paulo Evaristo Arns conseguiu esta proeza: um Ato Ecumênico na Catedral da Sé. Este evento, que reuniu mais de oito mil pessoas, representou uma das atividades que assinalam uma reação mais articulada da sociedade civil contra a ditadura, simbolizada por uma frase da atriz Ruth Escobar no Ato: "Até quando vamos continuar enterrando nossos mortos em silêncio?"3 (GASPARI, 2004, p. 183).

Se este acontecimento ainda repercute tão intensamente na sociedade é porque ainda há muito a ser dito, afinal os documentos dessa época, além dos depoimentos dos envolvidos e parentes, só começam a vir à tona, de maneira efetiva, no ano de 2012, em que foi criada a Comissão Nacional da Verdade ${ }^{4}$ (CNV), com a tarefa hercúlea de avaliar os fatos políticos transcorridos na sociedade brasileira de 1946 até 1988 . Bem diferente do desenrolar histórico dos países vizinhos que passaram por ditaduras como o Chile, a Argentina e o Uruguai. Nesses países houve reconhecimento dos crimes cometidos, enquanto no Brasil foi promulgada a Lei de Anistia em 1979, que teria anistiado todos que cometeram crimes no período anterior ${ }^{5}$.

Contam-se, nestes 39 anos de sua morte, inúmeros livros, filmes, reportagens e artigos científicos produzidos no Brasil e no exterior. No caso específico deste trabalho, iremos nos deter especialmente no documentário produzido pela TV Cultura "Vlado: 30 anos depois", sob a direção de João Batista de Andrade. À parte todos outros documentos que foram utilizados para esta análise, este documentário surge como uma rememoração do acontecimento. A proposta metodológica baseia-se, inicialmente, em uma análise

\section{Se 0 acontecimento ainda repercute muito na sociedade, é porque ainda há muito há ser dilto}

de conteúdo que toma o documentário como um indicador da vida social, que não encerra em si mesmo os sentidos possíveis, mas, ao contrário, dialoga com o contexto histórico no qual está inserido (LEAL e ANTUNES, 2011). Como enfoque integrante será utilizado o "paradigma indiciário" elaborado por José Luiz Braga (2008). O autor sedimenta o desenho metodológico deste paradigma oferecendo para os estudos em Comunicação uma abordagem focada em estudos de caso, permitindo, por meio de indícios provenientes de algum evento, remontar a uma realidade complexa. Esta tecitura intricada pode dar a ver "restos" ainda inexplorados do fenômeno que necessitam, para além de sua descrição, um exame crítico que problematiza as possíveis correspondências.
2- O operário foi dado como suicida, "enforcado" por uma meia, na mesma carceragem onde Vladimir Herzog fora encontrado igualmente "enforcado".

3-Vale registrar que o rabino Henry Sobel, também presente ao Ato, deu a ordem para que Herzog fosse enterrado não na ala dos suicidas, conforme tradição judaica, mas sim no centro do cemitério israelita.

4- Vale ressaltar a instalação, no dia 18 janeiro de 2013, da Comissão da Memória, Justiça e Verdade dos Jornalistas Brasileiros, presidida por Audálio Dantas, que, em trabalho conjunto com comissões estaduais, levantará os casos de violações dos direitos humanos cometidos contra jornalistas brasileiros no período de 1964 a 1988.

5- Houve nova tentativa de

reabertura de casos cujos corpos não apareceram, entretanto o

Supremo Tribunal Federal foi contrário a esta possibilidade na sessão de 29/04/2012, revalidando a Lei da Anistia, imposta pelo poder militar em 1979. 
Cabe destacar que os indícios apreendidos em um evento não remetem diretamente a realidade: é sua articulação (e a triagem de indícios realmente relevantes para o entendimento de um caso) que permite inferir as conjunturas do fenômeno e seu contexto amplo. Nesse sentido, após a avaliação do documentário "Vlado: 30 anos depois", será feita uma reflexão sobre memória e notícia, indícios impressos no material que despontam como possíveis inferências e que apontam para categorias insolúveis de apaziguamento da história que insiste em se manter conflituosa.

\section{Direito à narração do trauma}

Logo no início do documentário "Vlado: 30 anos depois", há uma cena emblemática, protagonizada pelo diretor do filme, João Batista de Andrade. Ela ocorre na Catedral da Sé, local onde aconteceu o culto ecumênico em homenagem a morte do jornalista. Aponta-se, por enquanto, um elemento que surge nestas primeiras imagens: o discurso de apresentação (e justificativa) da proposta do documentário por parte do seu diretor. Cabe aqui uma transcrição integral do trecho:

Este é um filme que eu deveria ter feito há muito tempo. Um filme sobre o jornalista Vladimir Herzog, assassinado numa prisão militar há 30 anos atrás (sic) num inesquecível 25 de outubro de 1975. Vlado, como era conhecido por familiares e amigos, era muito meu amigo, e sua morte me chocou profundamente. $\mathrm{Eu}$, que sempre filmava tudo, chocado, abatido com a morte do amigo, não filmei nada. Fiquei sempre com esta sensação de que havia uma falha na minha própria carreira, na minha filmografia. É uma falha que eu tento corrigir agora neste filme que eu dedico à memória do meu amigo e onde eu vou falar daqueles anos de chumbo. Esta será a cadeira dos depoimentos. É uma cadeira de diretor emprestada àqueles, que, com seus depoimentos pessoais, a partir de sua vivência daqueles anos mudos do regime militar, vão ajudar a reconstruir aqueles tempos, a prisão e a morte do Vladimir Herzog, o Vlado. Este será um filme certamente de poucas imagens. É claro que nós vamos ter imagens preciosas do Vlado, da Clarice, do culto ecumênico que marcou aquela época, que marcou praticamente o começo do fim da ditadura, e foi realizado nesta Catedral da Sé. Mas nós não temos as imagens dos torturadores, não temos a imagem do medo, a imagem dos aparelhos de repressão... Nós temos sim, a imagem dos nossos, as faces daqueles que nós perdemos e que foram perseguidos, torturados e mortos (DEPOIMENTO, Vlado: 30 anos depois).

Esta apresentação, primariamente, visa construir, de maneira projetiva, um acordo quanto à compreensão do que virá a seguir: trata-se da reconstituição, por meio de testemunhos daqueles que sofreram o trauma, da história apagada na memória e inscrita naqueles que a vivenciaram. Esta história muda, silenciada (como frisa o diretor), é a daqueles que não tinham direito à fala no período da ditadura militar. As imagens oficiais teriam encoberto experiências dissonantes ao que era veiculado na época como legítimo; experiências daquilo que seria a real manifestação de um regime repressor que censurava corpos e os faziam passar por vivências indescritíveis (a imagem do medo).

Se o direito de voz destas testemunhas do horror estava cerceado, sua manifestação, no documentário, é a prova de que tais relatos compõem uma realidade contrastante à versão oficial dos 
fatos. Mas se não há imagens para "provar" aquilo que foi obscurecido no período, e se as vivências são de ordem "pessoal", como é possível, por meio delas, reconstituir as texturas de uma época - dar a ver outra dimensão da história? Para Harvey Sacks (2007), este recurso está não em uma qualidade transmissiva das vivências, mas na impessoalidade e legitimação da experiência por meio de duas prescrições que conformam sua manifestação na linguagem ordinária: a participação nela daquele que galga o direito de relatá-la (ainda que indesejada), e a capacidade ulterior de poder descrevê-la de forma "comum".

$\mathrm{Se}$ o primeiro requisito soa correspondente às considerações habituais que seriam feitas sobre o relato de uma experiência (talvez fosse dito: é evidente que só pode discorrer sobre um trauma quem o vivenciou), por outro, neste caso em particular, um incômodo é gerado quando se diz que a narração da experiênciaé "comum" (ainda maisquando estão envolvidos choques profundos - como os contados por aqueles que estiveram nas sessões de tortura do DOICODI). A magnitude de tal incômodo fica evidente também nas palavras de Sacks, que se espanta ao identificar tal engrenagem na ação cotidiana: "relatos de experiências aparentemente ultrajantes, as quais imaginaríamos que deixariam as pessoas sem palavras, ou sobre as quais esperaríamos ouvir detalhes extraordinários, acabam sendo feitos de modo que percebemos a experiência como totalmente corriqueira" (2007, p. 170). Mas esta aparente incongruência pode ser resolvida se voltarmos alguns passos atrás. Quando se diz que a experiência é "de direito" de alguém quando esta pessoa participa dela, frisa-se o fato de que, na própria construção lexical, denota-se a não equivalência entre o sujeito que sofre algo e a ocorrência que gera o sofrimento. Este outro enfoque para o processo de experimentar, oriundo do pragmatismo filosófico, sublinha o caráter público e social de cada "vivência". Nesta mirada, a dinâmica intrínseca que perpassa as interações entre organismo e ambiente é reforçada, e mesmo havendo fases internas de experimentação, diz-se que elas são uma nuance receptiva (DEWEY, 2010) de um organismo que se vê em uma atmosfera que intercambia com ele continuadamente. A esfera impessoal da experiência, tal qual propõe Louis Quéré (2010), afeta um corpo que reage e que toma uma atitude e/ou assume uma postura. Este mesmo autor também diz, em outro texto, que "assumir uma atitude significa iniciar um movimento, dar início a uma ação enquanto tacitamente se projeta sua totalidade" (QUÉRÉ, 2011, p. 153, tradução dos autores).

No processo acima descrito, está demarcada a antecedência do social não só no ambiente comum de afetações e nas atitudes organizadas de reação, mas também na conduta que se pode assumir em face de uma experiência, extraída de um repertório partilhado e materializada em práticas inteligíveis de ação. Se "a expressão é uma manifestação encarnada nas ações, ou nos objetos expressivos, (...) de tal maneira que estes não existem previamente a esta expressão” (QUÉRÉ, 1991, p. 81), é em seu "aparecer" no comum que emerge sua participação em uma comunidade de comunicação que atribui uma carga de motivações ao seu "provável" trajeto de revelação, interpretando tal conduta em 
6- No decorrer deste tópico, os paralelos entre o pragmatismo e a etnometodologia serão traçados sem maiores explicações. Todavia, realça-se que suas intersecções ainda não estão de todo esclarecidas, e particularmente em trabalhos como os de Louis Quéré e Cédric Terzi (2011) e Anne Rawls (2011), são detalhadas polêmicas que envolvem o emprego de conceitos de ambas correntes como equivalentes. Sobretudo, tem-se aqui o cuidado de não criar este tipo de correspondência, tratando somente de aproximações que já estejam mais assentadas na atual conjuntura do debate científico.

7- Sacks fala aqui de narrativas trazidas à tona em conversações cotidianas, o que aparentemente passaria ao largo da atividade de entrevistar (que de antemão já confere relevância a história contada). Todavia, é interessante utilizar a mesma conceituação neste caso porque, resguardadas as diferenças, as entrevistas também detém similaridades para com as falas do dia-a-dia (tal qual Sacks et al (2003) concebem). um campo de racionalidades "normais" e segundo um conjunto de expectativas recíprocas sob o processo de interação e seus desdobramentos. De posse destas considerações, dizer que uma experiência só é narrável por um ator que detenha seus direitos legítimos é dizer que este ator, em um caso específico, pôde ser agenciado a levar a cabo tal experiência detendo as competências para apreendêla (tendo em conta que a "vivência" dele pode ser descrita, mas não transmitida - por estar intimamente atrelada a um contexto). Ainda que propriamente uma compreensãosó desponteem retrospectiva (tal qual Garfinkel (2006) havia sugerido), é quando o narrador remonta as origens daquilo pelo qual passou e atribui uma rede causal presumivelmente inteligível para quaisquer interlocutores que ouçam sua história ${ }^{6}$ que pode ser estabelecido um "trabalho interacional" de relatar e ouvir uma narrativa sobre uma experiência sofrida.

Nesta perspectiva, tratar como premissa a "normalidade" de um relato como base para o ato de "contar" uma história é dizer que mesmo os traumas mais dolorosos ou os choques mais inesperados só são parte de uma narrativa quando são parcialmente digeridos (geram uma atitude), a ponto de poderem ser animados na fala para outros interlocutores dentro de uma forma "habitual" de narração deste tipo de eventos. Como Sacks (1992, 2007) demonstra, a importância que uma experiência destas adquire, em seu relato, é derivada do espaço de tempo que ela escala para ser contada, da maneira como ela cria um campo de atração para si (instigando o ouvinte sobre detalhes da ocorrência), dos preâmbulos e prefácios envolvidos na narração do evento ápice da história ou ainda em seu surgimento brusco em um curso de fala ${ }^{7}$.

No enredo do documentário, a relevância e a gravidade dos testemunhos que entrecortam o filme mesclam-se em um "lugar de fala" (BRAGA, 1997) que, desde o discurso inicial do diretor, passando pelas entrevistas que ele faz com populares indagando sobre a identidade de Vladimir Herzog aos pés da Catedral da Sé e caminhando em direção à maneira como a vida do jornalista assassinado é contada por amigos que acompanharam sua trajetória e viveram com ele as experiências de tortura, indicam marcas de uma história negligenciada no período ditatorial e em vias de desaparecimento na memória corrente dos brasileiros. Por isto, a empreitada de João Batista não é somente a de reconstituir a carreira moral de um homem assassinado por um regime opressor, mas também a de remontar as experiências daqueles que foram vítimas de traumatismos indesejados, dolorosos, que marcaram uma época. Por esta razão, estas experiências, quando são contadas, encarnam uma dimensão comum, partilhada, não só na estrutura de sua narração, mas também na forma que adquirem no relato - a forma de uma história silenciada e agora reconstituída.

O prefácio da narrativa que dá vida ao documentário é uma lembrança da biografia de Herzog, do seu casamento, da viagem à Europa e do retorno ao Brasil logo no início da ditatura militar. Estes elementos são dispostos a fim de animar as motivações de uma figura icônica, memorial, repleta de ideais e interesses para com as classes desfavorecidas, injustiçadas. A insubordinação, resistência e bondade de Vladimir Herzog aparecem como insígnias de existência, 
uma aura que o recobriria ao longo de toda a vida e que estaria em claro contraste à imagem de terrorista associada a ele por órgãos oficiais ligados à ditadura nos idos de 1970 (nos depoimentos iniciais de D. Paulo Evaristo Arns, Rodolfo Konder, Fernando Morais e Miguel Urbano tal processo é intensificado).

No transcorrer do filme, esta alcunha associada à Vlado se mescla exatamente a história do país no ponto no qual sua carreira fica como pano de fundo de experiências de tortura vivenciadas e contadas por seus companheiros (Diléia Frate, Paulo Markun, Frederico Pessoa, Rodolfo Konder, entre outros). Sugestivamente, o título deste segmento do enredo é "Prisões". Nele, Vlado é o ponto de referência de um trauma de escopo social. Este trauma, privatizado no regime militar, ganha contornos públicos na narração. As histórias dos torturados, encadeadas umas nas outras, despersonalizam parcialmente as figuras dos narradores para convergir em uma teia habitual de experiências legítimas de injustiça. Esta dor, experimentada por Vlado e por tantos outros - tal qual o documentário lembra - é o retrato de uma memória indesejada na história do Brasil, ocultada nos anos de regime militar e resgatada de um possível desaparecimento na democracia dos anos 2000 (cabe lembrar que o filme foi rodado em 2005).

Mas a carga dramática destas entrevistas, dispostas em tom confessional (pelo plano fechado nas faces dos homens e mulheres que expiam seus sofrimentos ante a câmera) detêm legitimidade histórica não só por falarem de sequestros políticos, sessões de tortura brutais e até mesmo assassinatos movidos por causas ideológicas comuns nos governos de Garrastazu Médici e Ernesto Geisel. Evidentemente, a textura que amarra umas nas outras é a ilegitimidade histórica dos tais atos cruéis que violentaram aqueles que agora descrevem suas experiências em percursos mais ou menos similares (da abordagem pelos homens do DOI-CODI à chegada as instalações nas quais ocorreriam as séries de interrogatórios e de agressão por meio de "instrumentos" de tortura - ações estas que causariam degradação moral e física nestes sujeitos). Mas aquilo que confere a estes traumas uma maior autoridade é o seu grau intenso de indesejabilidade.

As experiências então ganham as colorações de um inesperado infortúnio, um choque arrebatador que inviabilizava qualquer reação plausível. Exatamente por isto elas se configuram como marcas insidiosas de um período histórico, porque falam de um sofrimento causado ao outro, sem possibilidades de impedimento ou evasão. No contexto do filme, as torturas devem ser sempre lembradas porque nos remetem às horrendas ações promovidas por humanos racionais, em aparente reciprocidade de expectativas com seus pares, mas que, sob determinadas circunstâncias, podem provocar e gerar dilacerações profundas em outros sujeitos. Sem uma constante rememoração das consequências de tais atos, anteriormente camuflados no regime ditatorial, corre-se o risco que, em arrombo, eles voltem a assombrar uma época, gerando, no processo, vozes que se tornam ruídos - não audíveis por aqueles que não as consideram pertencentes a indivíduos aos quais se deve demonstrar qualquer solidariedade ${ }^{8}$.

A palavra do testemunho de uma 
8- Ainda que este artigo não pretenda esmiuçar esta questão, é importante destacar a base destas proposições, provenientes da filosofia política de Jacques Rancière (1996). O autor se ocupou particularmente deste processo de ordenação dos corpos e de submissão de determinados sujeitos às vozes de autoridade. Nesses contextos, aqueles sujeitos, antes em reciprocidade de expectativas com seus pares, passam a não mais ser tratados como figuras dignas de respeito, transmutando-se, em um regime normativo, em ruídos opacos. experiência preenchida com estes matizes é, para Jacques Rancière, derivada da crença de que existem imagens intoleráveis. Isto "primeiro porque é o oposto da imagem que é idolatria, logo porque é a palavra do homem incapaz de falar, e, por último, porque é a do homem obrigado à palavra por uma palavra mais potente que a sua" (RANCIÈRE, 2009, p. 89, tradução dos autores).

As vítimas da ditadura contam suas histórias não por um desejo singular, mas por uma preocupação maior para com uma história que poderia ser esquecida em razão da ausência de imagens que poderiam expressar as mesmas dores (tal como João Batista sublinha). Mas "a imagem do medo", lembrada no início, não é passível de acesso, e quaisquer fotografias que captassem aquelas sessões de tortura provavelmente também não conseguiriam atingir a natureza da dor infligida. Isto porque o sentimento de inanição não é, da perspectiva do documentário, representado visualmente em consonância a uma aspiração de registro. "A verdadeira testemunha é aquela que não quer testemunhar" (idem, p. 88, tradução dos autores), diz, em tom crítico, Rancière. Isto porque tal presunção de maior realidade vinculada às experiências indesejadas não as torna, efetivamente, mais reais. Para o autor, "uma imagem jamais vai só. Todas [sejam elas escritas ou em audiovisual] pertencem a um dispositivo de visibilidade que regula o estatuto dos corpos representados e do tipo de atenção que merecem" (idem, p. 94, tradução dos autores).

Assim sendo, a realidade sensível que o documentário pretende alçar à memória coletiva, por meio das entrevistas com vítimas de tortura, é a da licitude dos traumas vivenciados, das opressões sofridas injustamente, e da figura de um jornalista assassinado em uma conjuntura de democracia inexistente. Agora veremos como este "dispositivo sensível" (para usar uma vez mais um conceito de Rancière (2009)) é acolhido na memória coletiva.

\section{Vestígios de uma história: memória e notícia}

Como diz Maurice Halbwachs (1990),

a memória necessita de sustentação para que seja revisitada. $\mathrm{Na}$ medida em que um jornalista de reconhecida competência foi morto, abriram-se as portas dos meios de comunicação e dos suportes materiais para que essa lembrança pudesse ser alargada, em especial a partir da década de 80 do século $\mathrm{XX}$, que é quando ocorre a distensão política no Brasil. Para Halbwachs, a vivência do coletivo é indispensável, pois o homem se define e se constrói pela cultura, já que se encontra inserido em contextos sociais. Os familiares, os amigos, os jornalistas e os defensores dos direitos humanos no Brasil, portanto, não deixaram esta história cair no esquecimento.

Poucas são as sociedades nas quais tenhamos vivido, seja em que tempo for, que não subsistam, ou que pelo menos não tenham deixado algum traço de si mesmas nos grupos mais recentes onde estamos mergulhados: a subsistência desses traços basta para explicar a permanência e a continuidade do próprio tempo nesta sociedade antiga, e que nos seja possível, a qualquer momento, nela penetrar através do pensamento.

(HALBWACHS, 1990, p. 127)

Os testemunhos do passado somente 
reverberam na sociedade quando esta acolhe estas lembranças. É preciso que existam pontos de contato suficientes entre o passado e o presente para que estas lembranças tenham sentido para a memória coletiva. Radicalizando ainda mais essa visão, Michael Pollak (1989) argumenta que em momentos de crise há uma disputa entre a "memória oficial" e as "memórias subterrâneas", o que garante o reconhecimento do campo problemático que determinadas memórias suscitam, contribuindo também para estudos específicos, como este aqui apresentado, que desconhece a continuidade como fio condutor do processo histórico, em que "objetos de pesquisa são escolhidos de preferência onde existe conflito e competição entre memórias concorrentes" (1989, p. 4).

Se o passado também se sustenta no presente, podemos dizer que a história é "arqueologia", como diz Michel Foucault (apud LE GOFF, 1999, p. 218), na qual as práticas e as intrigas decorrentes conduzem à construção crítica e questionadora do real. Ao rever os 30 anos entre a morte do Vlado e a inépcia de não-esclarecimento sobre o ocorrido, João Batista de Andrade fala de seu silêncio e do silêncio dos outros. Como argumenta Jacques Le Goff: "Devemos fazer o inventário dos arquivos do silêncio, e fazer a história a partir dos documentos e das ausências dos documentos". (1990, p. 220)

A única notícia que pôde ser dada à época, e somente dois dias após o assassinato de Herzog, foi essa: "Vladimir Herzog, depois de confessar sua ligação com o Partido Comunista Brasileiro, se suicidou na cela enforcando-se com o cinto de seu macacão". Esta é a nota oficial do Exército. A TV Cultura, entre inúmeras outras reportagens sobre $\mathrm{o}$ assunto ao longo de sua história, produziu um Cultura Retrô (2011), em que Fábio Perez, apresentador do Hora da Notícia, dirigido por Herzog no período de sua prisão, conta como ficou incomodado por não poder relatar o acontecimento. $\mathrm{E}$ é somente neste programa, 36 anos após o ocorrido, que o apresentador consegue simular a notícia:

Morreu na tarde de hoje, 25 de outubro de 1975, no DOI-CODI, o jornalista Vladimir Herzog, da TV Cultura. Informações de quem já esteve preso ali levantam a suspeita de que o jornalista tenha morrido em consequência de torturas brutais aplicadas por agentes do aparelho de segurança do regime. (CULTURA RETRÔ, 2011)

É lícito observar, portanto, que há uma memória em disputa (POLLAK, 1989), sendo possível "distinguir entre conjunturas favoráveis ou desfavoráveis às memórias marginalizadas (...). Conforme as circunstâncias, ocorre a emergência de certas lembranças, a ênfase é dada a um ou outro aspecto". (POLLAK, 1989, p. 8). Se, na época da morte de Vlado, os meios de comunicação eram proibidos de noticiar as torturas, os assassinatos e as prisões de inúmeros brasileiros, hoje, além dos inúmeros materiais produzidos e já citados, novas reportagens trazem à tona aspectos que ainda não foram devidamente esclarecidos.

A história reescrita por intermédio desse dispositivo de análise, no caso, o documentário, procura mostrar falas e imagens daqueles que nunca se calaram, que buscaram expor, mesmo 
que de maneira clandestina, outro olhar sobre esse período histórico. Como reafirma o diretor, logo no início do documentário, "não há imagens dos torturadores (...), do medo e a imagem dos aparelhos de repressão", posto que a história oficial tratou de ocultar da sociedade as experiências traumáticas que estariam inscritas nestas imagens. Como diz Michael Pollak "o trabalho de enquadramento da memória se alimenta pelo material fornecido pela história" (1989, p. 9), o que quer dizer, neste caso, que a ausência de testemunhas do discurso oficial sobre a ditadura militar abre uma clivagem nesse processo. $\mathrm{O}$ silêncio que foi imposto pelo discurso oficial, de alguma maneira, contribuiu para a construção de discursos nãohegemônicos sobre o acontecimento.

\section{O espaço público ocupado por memórias e reverberações quando documentos são colocados à disposição}

Como já falado, o que este documentário apresenta então é uma dimensão comum ao acontecimento "ditadura militar" a partir dos relatos daqueles que passaram por essa experiência. Nas palavras de Pollak, apesar dos entraves implicados na captação de lembranças pelos dispositivos confeccionados para esta finalidade, "o filme é o melhor suporte para fazê-lo: donde seu papel crescente na formação e reorganização, e portanto no enquadramento da memória" (1989, p. 11). Como ainda argumenta o autor: "Ele se dirige não apenas às capacidades cognitivas, mas capta as emoções". (1989, p. 11)

Se as memórias individuais (mesmo participando de articulações sociais organizadas) persistem na tentativa de contar essa história é porque a memória social sobre esse acontecimento ainda não reflete todas as matizes possíveis de serem abarcadas. Se nossa memória se apoia na história vivida e não na história aprendida (HALBAWACHS, 1990) é porque reflete as diversas relações humanas existentes na sociedade e também porque pode conferir determinados sentidos a determinadas épocas, participando ativamente da construção da história.

\section{Considerações finais}

Ao discutir o processo de produção da notícia, Fischman (1983) questiona, entre outros aspectos, "como os repórteres conferem sentido e significado às coisas com as quais tomam contato" (p. 24, tradução dos autores). Esta indagação não diz apenas do ponto de vista do repórter, mas da condição social em que "os fatos" estão inseridos. Isto quer dizer que os jornalistas são responsáveis pela organização dos acontecimentos transformados então em notícias, mas que não estão sozinhos nesta tarefa. Há uma produção social do fato, sendo inúmeros os fatores envolvidos neste processo.

Os meios de comunicação, como um dos lugares de constituição da memória coletiva, não conseguiram, à época da morte do jornalista Vladimir 
Herzog, veicular estas informações, mas conseguem hoje, com o advento da Comissão Nacional e das Comissões estaduais da Verdade, dar vazão a inúmeras reportagens que incidem sobre este acontecimento. E não foi somente pela presença da censura que esta $e$ outras matérias sobre $\mathrm{o}$ período não puderam ser veiculadas; foi também pela impossibilidade das pessoas falarem, pois lembranças traumatizantes "esperam o momento propício para serem expressas (...). O longo silêncio sobre o passado, longe de conduzir ao esquecimento, é a resistência que uma sociedade civil impotente opõe ao excesso de discursos oficiais". (POLLAK, 1989, p. 5)

O espaço público é então ocupado por estas memórias e reverberações, na medida em que muitos documentos e depoimentos são, finalmente, colocados à disposição para jornalistas, historiadores, pesquisadores e a sociedade em geral. A própria história reforça sua condição conflituosa, em que vários grupos disputam o seu enquadramento. No caso específico, vale registrar que, após recomendação da CNV e atendendo solicitação da família Herzog, a Justiça de São Paulo determinou a mudança do registro de óbito de Vlado. O atestado, que antes apresentava a causa da morte por "asfixia mecânica", teve sua redação alterada para morte em decorrência "de lesões e maus-tratos sofridos em dependência do II Exército - SP (DoiCodi)".
Ayres Britto, Ministro do Supremo Tribunal Federal, ao proclamar seu voto contrário à revalidação da Lei da Anistia (ver nota de rodapé $n^{\circ} 5$ ), reforçou que "os crimes hediondos não foram incluídos no texto da Anistia. Quem redigiu esta Lei não contemplou os crimes de torturadores" (2012). Acrescentando ainda que "a humanidade tem o dever de odiar os seus ofensores porque o perdão coletivo é falta de memória e de vergonha" (2012). A sociedade brasileira parece não se ausentar nesse sentido, afinal, nas palavras de Jacques Le Goff, "a memória é um elemento essencial do que se costuma chamar identidade, individual ou coletiva, cuja busca é uma das atividades fundamentais dos indivíduos e das sociedades de hoje" (1990, p. 44).

O dispositivo sensível, que nomeia Jacques Ranciére (2009), tanto pode ser o documentário que, mais do que apresentar discursos, insiste em extravasar as experiências que não queriam ter "sido", quanto pode ser a imagem de Vlado congelada em uma fotografia criada pelos aparelhos repressores e acionada como uma lembrança indesejada, mas ainda não resolvida. Nesse sentido, o documentário produzido pela TV Cultura e dirigido por João Batista de Andrade reconstitui uma experiência que é comum por afetar socialmente grupos em ação e que continua a reverberar na memória coletiva, em especial nos meios de comunicação e no jornalismo.
1- O nome imprensa alternativa, também chamada de nanica, era utilizado para classificar mais de uma centena de publicações que surgiram entre 1964 e 1980. Opinião, Pasquim e Movimento foram os periódicos mais importantes entre esses jornais e revistas, muitas vezes de periodicidade incerta. Sobre o tema cf. Kucinski (1991). 


\section{Referências bibliográficas}

BRAGA, José L. "Lugar de fala" como conceito metodológico no estudo de produtos culturais e outras falas. In: FAUSTO NETO, Antônio; PINTO, Milton (Orgs.). Mídia e Cultura. Rio de Janeiro: Diadorim/Compôs, p.105-120, 1997.

Comunicação, disciplina indiciária. In: MATRIZes, n.2, São Paulo, p.73-88, 2008.

BRITO, Ayres. Rejeitada Ação contra Lei da Anistia: veja voto de dois ministros. Disponível em: http://www.youtube.com/watch?v=5ranNPsDDAk. Acesso em: 20 outubro 2013.

DANTAS, Audálio. As duas guerras de Vlado Herzog: Da perseguição nazista na Europa à morte sob tortura no Brasil. Rio de Janeiro: Civilização Brasileira, 2012.

DEWEY, John. Arte como experiência. São Paulo: Martins Fontes, 2010.

FISHMAN, Mark. La fabricación de la noticia. Buenos Aires: Ediciones Tres Tiempos, 1983.

GARFINKEL, Harold. Estudios en etnometodología. Bogotá: Universidad Nacional de Colombia, 2006.

GASPARI, Elio. A Ditadura Encurralada: O sacerdote e o feiticeiro. São Paulo: Companhia das Letras, 2004.

HALBWACHS, Maurice. A memória coletiva. São Paulo: Vértice, 1990.

LEAL, Bruno S.; ANTUNES, Elton. O acontecimento como conteúdo: limites e implicações de uma metodologia. In: LEAL, Bruno S.; ANTUNES, Elton; VAZ, Paulo B. (orgs). Jornalismo e Acontecimento: percursos metodológicos. Florianópolis, Insular, v. 2, 2011.

LE GOFF, Jacques. História e Memória. Campinas, São Paulo: Editora da Unicamp, 1990.

MARKUN, Paulo. Meu querido Vlado: A história de Vladimir Herzog e o sonho de uma geração. Rio de Janeiro: Objetiva, 2005.

POLLAK, Michael. Memória, Esquecimento, Silêncio. In: Estudos Históricos, v.2, Rio de Janeiro, p. 1-15, 1989.

QUÉRÉ, Louis. De um modelo epistemológico da comunicação a um modelo praxiológico. Traduzido por Lúcia Lamounier Sena e Vera Lígia Westin (mímeo). Do original: "D’un modèle épistemologique de la communication à un modèle praxéologique”. In: Réseaux, n 46/47. Paris: Tekhné, p. 69-90, 1991.

O caráter impessoal da experiência. In: LEAL, Bruno S; GUIMARÃES, César; MENDONÇA, Carlos C. (Orgs.). Entre o sensível e o comunicacional. Belo Horizonte: Autêntica Editora, 2010. 
Towards a social externalism: pragmatism and ethnomethodology.

In: European journal of pragmatism and american philosophy, n.3, v.2, p.156174, 2011.

; TÉRZI, Cedric. Some features of pragmatist thought still remain insufficiently explored in ethnomethodology. In: Qualitative Sociology, n.34, v.1, p.271-275, 2011.

RANCIÈRE, Jacques. O desentendimento: política e filosofia. São Paulo: Ed 34, 1996.

. The intolerable image. In:

. The

emancipated spectator. Brooklyn: 2009.

RAWLS, Anne. Harold Garfinkel, ethnomethodology and defining questions of pragmatism. In: Qualitative Sociology, n.34, v.1, p.277-282, 2011.

SACKS, Harvey. Lecture 2. Features of a recognizable "story"; story prefaces; sequential locator terms; lawful. In: Lectures on conversation. Oxford: Basil Blackwell, 1992.

. Ocupando-se em “ser comum”. In: Veredas, v.1, Juiz de Fora p.165181, 2007. Do original: SACKS, Harvey. On doing "being ordinary”. In: ATKINSON, John; HERITAGE, John (Orgs.). Structures of social action: studies in conversation analysis. Cambridge: Cambridge University Press, 1984.

; SCHEGLOFF, Emanuel; JEFFERSON, Gail. Sistemática elementar para a organização da tomada de turnos para a conversa. In: Veredas, v.7 Juiz de Fora, p.9-73, 2003. Do original: SACKS, Harvey; SCHEGLOFF, Emanuel; JEFFERSON, Gail. A simplest systematic for the organization of turn-taking for conversation. In: Language, v. 50, Baltimore, p.696-735, 1974.

\section{Vídeos}

ANDRADE, João Batista. Vlado: 30 anos depois. Documentário, São Paulo, TV Cultura, 2005. 1h30min.

CULTURA RETRÔ - 27/10/2011. Disponível em: http://tvcultura.cmais.com.br/ culturaretro/vlado-quintal-28-10-cmais Acesso em 21 outubro 2013.

Este artigo e todo o conteúdo da Estudos em Jornalismo e Mídia estão disponíveis em https://periodicos.ufsc.br/index.php/jornalismo 